
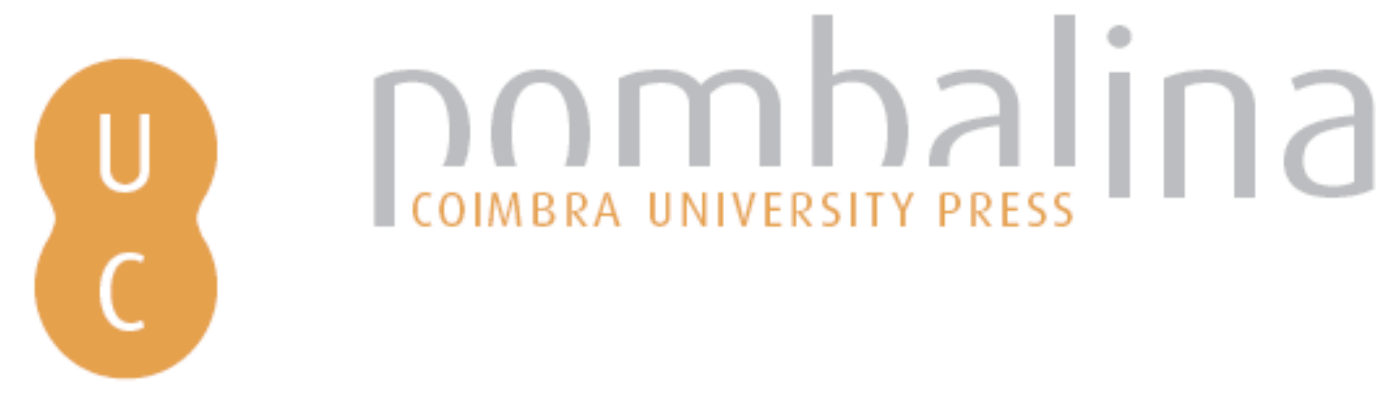

\title{
Sócrates e a Paideia falhada de Alcibíades
}
Autor(es):
Fialho, Maria do Céu
Publicado por: Centro de Estudos Clássicos e Humanísticos
URL persistente:
URI:http://hdl.handle.net/10316.2/32119
DOI:
DOI:http://dx.doi.org/10.14195/978-989-721-062-4_2

Accessed : $\quad$ 26-Apr-2023 00:26:36

A navegação consulta e descarregamento dos títulos inseridos nas Bibliotecas Digitais UC Digitalis, UC Pombalina e UC Impactum, pressupõem a aceitação plena e sem reservas dos Termos e Condições de Uso destas Bibliotecas Digitais, disponíveis em https://digitalis.uc.pt/pt-pt/termos.

Conforme exposto nos referidos Termos e Condições de Uso, o descarregamento de títulos de acesso restrito requer uma licença válida de autorização devendo o utilizador aceder ao(s) documento(s) a partir de um endereço de IP da instituição detentora da supramencionada licença.

Ao utilizador é apenas permitido o descarregamento para uso pessoal, pelo que o emprego do(s) título(s) descarregado(s) para outro fim, designadamente comercial, carece de autorização do respetivo autor ou editor da obra.

Na medida em que todas as obras da UC Digitalis se encontram protegidas pelo Código do Direito de Autor e Direitos Conexos e demais legislação aplicável, toda a cópia, parcial ou total, deste documento, nos casos em que é legalmente admitida, deverá conter ou fazer-se acompanhar por este aviso.

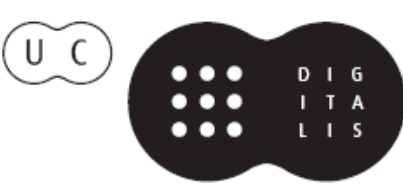


Colecção Autores Gregos e Latinos Série Ensaios

\section{Carmen Soares \\ José Ribeiro Ferreira Maria do Céu Fialho}

Ética e Paideia em Plutarco 


\section{Sócrates e a Paideia Falhada de Alcibíades}

Maria do Céu Fialho

Em muitas das Vitae de Plutarco apercebemo-nos de uma espécie de tensão agonística entre valores naturais, que se deixam adivinhar nas potencialidades que o seu carácter parece revelar à partida, e estímulos externos ou contingências que, muitas vezes, póem à prova e se sobrepóem a essa natureza promissora. Do resultado dessa luta, seja ele já perceptível na juventude, ou na maturidade ou no fim da vida, decorre a configuraçáo final do ethos do herói.

Podemos, entre outros, dar o exemplo de Alcibíades jovem, em quem o próprio Sócrates vislumbrou, mais além da sua beleza externa, marcas de euphyia e arete que era necessário ajudar a desenvolver pela filosofia $(A l c .4 .1.) .{ }^{1}$ Teseu, por sua vez, enquadra-se naquele tipo de heróis que, a partir de uma juventude promissora, guiada pelo exemplum interiorizado de Héracles que representou para ele um factor de auto-educaçáo e determinação de comportamento, se veio a perder na maturidade. A coragem e philanthropia de Teseu perderam coerência e deixaram de dar consistência ao seu ethos no momento em que o fundador de Atenas cedeu a uma forma de philautia decorrente do desejo de satisfazer os seus próprios impulsos. Como terceiro exem-

${ }^{1}$ Sobre a importância da Filosofia no desabrochar das virtudes e no caminho para uma eudaimonia mais qualitativa da alma em Plutarco vide F. Becchi 1999: 25-43. 
plo, recorde-se Demétrio (52) que, como prisioneiro de Seleuco, se entregou, nos últimos anos da sua vida, ao império do vinho e da comida, uma vez que não lhe restava esperança de recuperar a liberdade.

Assim, valores e contra-valores, vícios e virtudes se vão manifestando em acto até ao apuramento final do que vale o exemplo pedagógico de uma biografia. Esta definição dinâmica de carácter através das acções é de raiz aristotélica ${ }^{2}$ - reconhece-se toda a filosofia de acção analisada em Ética a Nicómaco. Por sua vez, a força de uma arete inata, que representa a superioridade platónica da alma sobre o corpo, está presente no reconhecimento que Plutarco faz da existência de um potencial de qualidades morais, reveladas à partida, num ser ainda jovem. Elas são reforçadas pela educação, que o preparam para defrontar agentes externos, como a tyche e os seus caprichos ou a pressão do contexto social. É nesse confronto que aquilo que podemos designar como o "carácter estruturado" se define, de acordo com a força moral do herói. É nesse confronto que Plutarco conduz o leitor a avaliar o quanto pode a força da educaçáo (se acaso reforça uma boa physis) ou o quanto pode a força da Fortuna, seja ela cruel, instável, ou demasiado próspera.

Neste contexto revela-se particularmente interessante o caso da vida de Alcibíades. Sobre esta fascinante e polémica figura afirma Plutarco (4.1-2) — curiosamente no mesmo capítulo inicial em que refere, de forma enfática, a força positiva da presença de Sócrates:

${ }^{2}$ A. Pérez Jiménez 1973: 103 ss. 
Já muitos homens de origem nobre vinham rodeando Alcibíades e cortejavam-no, mas enquanto se tornava evidente que os outros se sentiam atingidos e atraídos pelo esplendor da sua juventude, o amor que Sócrates lhe devotava constituía um testemunho irrefutável da natural disposição do jovem para a virtude. Aquele, ao notar que os dons inatos do jovem se manifestavam e transpareciam no seu aspecto exterior, teve receio que a riqueza, a condição social, a multidão de cidadãos, de estrangeiros e de aliados o estragasse pela adulação e com favores. E então protegia-o, em atitude vigilante, como se ele fosse uma planta em flor, de que se cuida para não deixar que perca o fruto ou que seque. De facto, não há pessoa alguma a quem a fortuna (tyche) tivesse de tal modo rodeado e cumulado dos chamados bens, exteriores, a ponto de se tornar invulnerável em relação à filosofia e insensível a palavras francas e mordazes.

E é na Vita de Alcibíades que irei centrar este estudo. O passo citado pertence ao conjunto de capítulos iniciais que se ocupam, de modo aparentemente desordenado, da ascendência e de episódios da infância e adolescência desta figura. Não encontramos nesta biografia propriamente um prólogo. ${ }^{3}$ Plutarco entra directamente no assunto: Alcibíades descende de heróis da saga épica, ao mesmo tempo que a linha materna o liga aos Alcmeónidas. Seu pai combateu os Persas em Artemísio e os Beócios em Coroneia, onde morreu. Péricles e Arífron foram seus tutores, teve uma mulher da Lacónia como ama e como pedagogo um homem chamado Zópiro.

${ }^{3}$ Ph. Stadter 1988: 275-295 distingue dois tipos de prólogo e inclui este no grupo dos "proémios integrados". 
Plutarco antecipa aqui, como uma espécie de determinante da futura sorte de Alcibíades, o papel da presença de Sócrates na sua vida: foi a eunoia e a philanthropia do filósofo que contribuiram substancialmente para a doxa de que o jovem viria a gozar (1.3.).

Da sua beleza física imperecível, que o acompanhou até à morte, Plutarco passa para a referência às inconsistências de carácter reveladas na idade adulta e que relaciona com pragmasi megalois kai tychais polytropois (2.1.). O autor sublinha, nestas consideraçôes prolépticas, como se viria a reconhecer em Alcibíades um philoneikos e philoprotos, para regressar à sua infância e juventude e ilustrar, com breves anedotas, o carácter que já se anunciava. A sua rebeldia para com os mestres denuncia até que ponto este jovem promissor é avesso à influência da educação e sabe desde cedo, por intuição, jogar com as circunstâncias e manipular, servindo-se dos seus dotes. No entanto, esta ordenação aparentemente caótica dos capítulos iniciais da vida de Alcibíades contém uma semiótica própria. ${ }^{4}$ Plutarco joga com uma espécie de prefiguração do que será a própria anarquia da vida do biografado, embora os episódios relatados corroborem a sua extrema incrível capacidade de resposta rápida às situaçóes e o seu arrojo. Uma leitura mais superficial deixaria o leitor criar expectativas de estar perante um indivíduo genial - que o era - de quem se poderia vir a esperar um brilhante futuro.

${ }^{4}$ Demonstra-o Th. Duff 2003: 94 ss. 
Do mesmo modo, o fim da vida de Alcibíades condensa, numa espécie de simbologia, a síntese da sua própria existência: é um fim envolto em incerteza, polémico, escandaloso e ambíguo pela própria cosmética feminina com que aparece no seu sonho premonitório e pelas vestes de cortesã com que, por fim, Timandra o cobre. $^{5}$

A ambiguidade remete para o episódio de juventude de luta livre com o adversário, que o acusa de recorrer a processos pouco ortodoxos (2.2.): ${ }^{6}$

Tu mordes, ó Alcibíades, tal como o fazem as mulheres!

O processo de condensação simbólica constitui um recurso de escrita do gosto de Plutarco, para tornar mais forte o poder de sugestáo do quadro final sobre o percurso que a ele leva. Outros desfechos de biografias o ilustram, como, por exemplo, o da de Teseu, de Cato Minor ou de César. Esta última envolve na narrativa o fim do assassinado, do assassino e da república romana. Diga-se, de passagem, que se trata de um recurso próprio da narrativa poética e que provoca, por parte do leitor, uma adesão ao texto que está para além da razão e que se prende com os efeitos de sugestão e representação próprios da poiesis.

${ }^{5}$ Sobre o significado dos sonhos nas Vidas de Plutarco vide F. E. Brenk 1975: 336-349.

${ }^{6}$ Th. Duff 2003: 96 sublinha o modo como este episódio, entre outros, funciona como uma prefiguração da ambiguidade sexual do biografado. Esta atingirá o seu ponto culminante no final da Vida. 
As relaçôes de sangue de Alcibíades ligam-no aos Alcmeónidas, simultaneamente ilustres e ligados a um caso passado de sacrilégio. A coragem do pai parece ser espelho dos futuros feitos militares do filho. Não deixa de ser expressivo, no discurso de Plutarco, dar aquele como combatente contra Persas e contra Gregos, assim como anotar o papel de tutor de Péricles, cuja influência e exemplo parece nada ter significado para o jovem, em simultâneo com um pormenor aparentemente insignificante: o da ama, oriunda de um espaço ligado a Esparta.

Por outro lado, o registo da beleza física antecede consideraçôes sobre o ethos de alguém que parece preso não só das alteraçóes da fortuna, mas da sua própria beleza que o condiciona a ser admirado e assediado sem ter estrutura ética para resistir à pressão desse assédio. Alcibíades apresenta-se, à partida, condicionado por essa beleza, pelo arrojo demonstrado, por um carácter fraco e volúvel e por uma inteligência brilhante a desempenhar um agitado protagonismo na vida de Atenas. Frequentemente utiliza Plutarco a conjugação tolma kai synesis para definir essses actos de arrojo que vão da infância ao fim da vida. Não é andreia o termo escolhido - mas este é o termo que Plutarco selecciona, em contrapartida, para designar a coragem de Coriolano e sublinha, na biografia correspondente, que este termo equivale ao que os Romanos designam por arete. Isto é, adivinhamos no grego do autor, o esforço de equiparação ao latim uirtus. Com ela se conjugam a temperança e o sentido de justiça 
(enkrateia kai dikaiosyne). O lado negativo do seu carácter reside na extrema arrogância e orgulho que o hão-de perder.

O começo da biografia de Coriolano prepara já a synkrisis entre as duas Vitae, na medida em que responde, de alguma forma, ao paralelismo entre a infância das duas personagens. Coriolano também ficou órfão de pai na infância, mas manteve sempre, em relação à mãe, um grande afecto. Em Alcibiades não se fala, à partida, de afectos, mas de grupos de jovens que rodeavam o protagonista e o seguiam. A Coriolano faltou-lhe a presença vigorosa de um pai e a educação que desenvolvesse as virtudes do seu carácter e inteligência, refreando os defeitos e impulsos, como a cólera, a que era propenso, e a arrogância. Com a bela imagem de matriz platónica ${ }^{7}$ realça Plutarco o papel necessário que a educação exerce sobre as naturezas nobres e os caracteres potencialmente bons (Cor.1.3):

O mesmo Márcio, por outro lado, confirmou a razão de quantos pensam que uma natureza nobre e generosa, se lhe falta a disciplina, é capaz de produzir, juntamente com os bons frutos, outros que não têm qualidade, como acontece em relação a um solo fértil que não tenha sido objecto dos cuidados do agricultor.

Estas consideraçóes constituem uma espécie de resposta ao itinerário de juventude de Alcibíades. Este, em contrapartida, teve tutores de prestígio, teve quem

${ }^{7}$ Cf. Platão, Rep. 491, d-e. 
se ocupasse da sua educação e, sobretudo, contou com a dedicação de Sócrates, empenhado em fazer desabrochar o que de melhor havia no jovem. O que, à partida, se pode considerar o ethos potencial de Alcibíades, com as boas e más qualidades que exigiam a intervenção de um educador, mas também o esforço do próprio, foi sendo sujeito a agentes externos contraditórios, de modo a que o de que pior havia em Alcibíades prevaleceu, como resposta a um destes tipos de agentes.

Por um lado, consideremos o conjunto daqueles que admiravam o corpo e manifestaçóes físicas de Alcibíades - os aduladores, os jovens movidos pelo impulso de um eros físico, que nele exacerbavam o desejo de satisfazer o prazer imediato. A este estímulo facilmente se associa o prazer do vinho e a embriaguez, a imoderação nos banquetes e na vida pública, a procura da glória fácil, ainda que com o sacrifício da coerência, da correcção ética, do bem da cidade. O episódio relatado por Plutarco em 4.5 serve como de pórtico a um historial de atitudes de insolência e prepotência de Alcibíades, manifestadas no espaço de convívio social, como é o do banquete, provocadas pela imoderação na bebida e pela consciência de que as pessoas que humilha estão sob o império do fascínio que ele exerce, como é o caso de Ânito: ${ }^{8}$

Acontece que este homem, que estava apaixonado por Alcibíades, ao convidar alguns convivas para a ceia o convidou também a ele.. Alcibíades declinou o convite, mas depois

${ }^{8}$ Sobre este assunto veja-se M. C. Magán 1999: 171-180. 
de ter bebido em excesso em sua própria casa, juntamente com alguns amigos, fez-se, com tal comitiva, ao caminho até casa de Ânito. Postou-se na soleira da sala de banquete deste homem e, ao ver as mesas cobertas de taças de prata e ouro, deu ordem aos escravos para se apossarem de metade e a levarem para sua casa. E nem sequer se dignou entrar. Depois de ter cometido esta desfaçatez, foi-se embora. Os convivas ficaram indignados e disseram que Alcibíades se tinha comportado com Ânito de modo grosseiro e sumamente insolente (bybristikos kai hyperephanos).

Esta intervenção de Alcibíades a meio do banquete do antagonista de Sócrates recorda um outro Banquete, o de Platão, onde a problemática de eros é discutida e em que Alcibíades, chegando também com atraso, manifesta não estar apto a passar além do plano da erótica do mundo sensível.

A corrupção de Alcibíades arrasta a corrupção de companheiros da sua geração. E se as adversidades da tyche podem funcionar como uma espécie de teste de carácter, enfraquecê-lo mas também fortificá-lo, no caso de Alcibíades o factor tyche, como se viu no passo acima citado (4.2), por lhe ter sido excepcionalmente favorável, não o pôs à prova e arredou-o da disposição de alma para reconhecer as limitaçóes do humano e a necessidade de uma reflexão filosófica e da adesão a uma filosofia prática.

De facto, as alusôes à presença de Sócrates estão contidas nesta primeira fase da vida do jovem e aparecem intencionalmente entremeadas com os desmandos do protagonista. A referência à relação erótica física com 
Ânito, fonte de arrogância e desequilíbrio para Alcibíades (4.5), aparece antecedida da referência ao eros de Sócrates por Alcibíades, ao qual se contrapôe (4.1). É que este representa o eros direccionado para as qualidades inatas, que se dedica a ajudar a desenvolver na alma do eroumenos. Numa espécie de vivência caótica Sócrates representa a voz da Filosofia, o apelo da ordem e à ordem da alma, pela askesis de uma filosofia prática que faz desenvolver no indivíduo o amor ao Belo e ao Bom, nunca separando eticamente aquele deste. Mas Sócrates constituia uma excepção. Apenas Sócrates, pela visão privilegiada de um daimonios que depurou a capacidade de ver através do desprendimento do plano do material ao cultivar a verdadeira Filosofia como modo de vida verdadeiro, podia vislumbrar as qualidades, em estado seminal , que existiam na alma de Alcibíades e que era urgente fazer frutificar. Este constitui o segundo agente que luta por anular o primeiro de que se falou. No entanto, a estratégia das referências à acção e às intençôes de Sócrates faz perceber que a sua acção se tornará ineficaz, sobre um jovem envolvido por um turbilhão de estímulos que apelam para o que de pior há em si, reforçados por uma tyche em aparência excepcionalmente favorável, como agente externo - exothen. Assim o atesta o passo acima citado (4.1-2).

Segue-se a referência à tyche excepcional, que tornou o jovem "invulnerável em relação à filosofia”, como antecipação, à maneira da tragédia esquiliana, entremeada no discurso sobre a influência de Sócrates na sua pessoa e a atracção por Sócrates, que o levava a 
ouvi-lo com encanto, como quem ouve um amante, e a tornar-se companheiro habitual do filósofo, desprezando "amantes ricos e famosos". Terá Alcibíades sido alguma vez verdadeiramente tocado pela sabedoria socrática? A planta frágil possuia qualidades para isso, mas o campo em que nasceu (antecipando a imagem da Vita de Coriolano) e todas as condiçōes adversas ao seu crescimento tornaram vã a acção de Sócrates. É o que Plutarco pretende mostrar à partida com a organizaçáo do seu discurso. Mais tarde será mais explícito, ao referir ten tes physeos anomalian deste homem (16.6). Nem o próprio Alcibíades se apercebeu, na fase de proximidade de Sócrates, que a acção benfazeja do génio filosófico não encontrava verdadeiramente condiçóes para exercer a sua eficácia (4.3-4):

...ele chegou a pensar que a acção de Sócrates constituía, de facto, um gesto de assistência dos deuses para cuidado e salvação da juventude. Assim, desprezando-se a si mesmo e admirando o seu amigo, amando a benevolência deste, de quem respeitava a virtude, ele alcançou, sem se aperceber, uma "imagem do amor", consoante diz Platáo, "em resposta ao amor", e toda a gente ficava admirada por o ver comer com Sócrates, exercitar-se com ele na luta, e partilhar a sua tenda, enquanto se mostrava áspero e intratável com os seus outros admiradores...

Segue-se de imediato o episódio da embriaguez e excessos no banquete de Ânito.

A partir daí, o motivo da acção de Sócrates é tratado por Plutarco com uma hábil expressividade, de 
modo a deixar perceber que a influência do filósofo em Alcibíades se vai progressivamente perdendo, como se o crescimento desse rebento com potencialidades, na alma do jovem, fosse asfixiado por ervas daninhas (6.1):

Mas o amor (eros) de Sócrates, embora contasse com muitos e poderosos rivais (antagonistas), de algum modo dominava Alcibíades. É que o filósofo fazia apelo ao que de bom havia na sua natureza e as suas palavras dominavam-no, atormentavam o seu coração, até lhe provocar as lágrimas. Todavia, por vezes, o jovem deixava-se dominar pelos aduladores, que lhe ofereciam inúmeros prazeres (hedonas), escapava à alçada de Sócrates e sujeitava-se a ser perseguido como caça, por este, tal como se fosse um escravo fugitivo. E todavia só por Sócrates ele sentia medo e nutria reverência. Quanto aos restantes, desprezava-os.

Não é já a imagem do amor, segundo Platão, que Alcibíades sente que Sócrates nele consegue despertar, mas o medo e a reverência, de que tenta escapar, enquanto o filósofo tenta, já em vão, exercer o seu múnus nesta alma prestes a perder-se no turbilhão dos prazeres. A eficácia da influência de Sócrates é agora posta a par da dos aduladores, como seus rivais, não é já constante e não se impõe pela sedução natural. Expressiva é a imagem do escravo fugitivo.

O retrato de Sócrates, como um ser excepcional, assistido pelo daimon (17.4), como só o pode ser alguém que cultiva em tão alto grau a filosofia prática e a ela conduz os seus formandos, está em perfeita sintonia com a visão tida com respeito a Sócrates na época de 
Plutarco e com o próprio tratamento da figura em outras obras de Plutarco, sob influência do modelo dos diálogos platónicos. O seu De genio Socratis, em especial, é perceptível em vários passos das diferentes Vitae. ${ }^{9}$

A última tentativa de Sócrates para fazer desabrochar o sentido dos valores, em Alcibíades, é já uma tentativa de recurso extremo, na sequência da batalha de Potideia, para que o mérito que verdeiramente cabia ao próprio Socrates, mais do que a Alcibíades, fosse reconhecido a este. Comenta Plutarco (7.5):

Em rigor, a recompensa de mérito cabia a Sócrates; mas os comandantes, tendo em conta a condição social de Alcibíades, deixaram transparecer o desejo de atribuir a este a glória. Sócrates, que desejava incrementar no jovem a ambição por empresas nobres (to philotimon en tois kalois), foi o primeiro a testemunhar em seu favor e pediu que o amigo recebesse uma coroa e uma armadura completa ...

Isto é, o filósofo faz um apelo desesperado a algo que é, por vezes, em Plutarco, negativamente valorizado - a philotimia - e que constitui um traço de carácter acentuado em Alcibíades, para o direccionar para as boas acçôes e, assim, para o que é belo, sendo bom. ${ }^{10}$

${ }^{9}$ Platão e Xenofonte desempenharam um papel decisivo, entre outros autores, como Aristóteles, Demétrio de Falero, Panécio, para a configuraçáodo retrato de Sócrates e para a sua popularidade na Antiguidade tardia. Em relação ao caso específico de Plutarco, vide J. P. Hershbell 1988: 365-382.

${ }^{10}$ Acepçóes negativas de philotimia estão atestadas, por exemplo, em relação com doxomania (Plu. Sull. 7), kenodoxia (M. 57d), philoneikia (Ages. 23. 33), philarchia (M. 785 sq.). Como acepçóes 
$\mathrm{Na}$ retirada dos Gregos em Délios, a retirada de Sócrates, ainda que protegida por Alcibíades, quase assume o valor simbólico da saída do filósofo da vida deste homem.

Toda esta tensão de forças parece traduzir-se estilisticamente no jogo de palavras compostas com o radical phil-: à philanthropia de Sócrates (1.2) ficou a dever um contributo fundamental para a sua fama (doxa), mas o facto de se manifestar, desde cedo, philoneikos e philoprotos (2.1), fizeram-lhe alcançar fama fácil e protagonismo sem virtude, de modo a se tornar impenetrável à philosophia do mestre (4.2). Sócrates diagnostica nele uma philotimia que tenta encaminhar para o eticamente correcto, mas em vão o faz. Essa philotimia desenvolverse-á com a adulação, com a consciência dos seus dotes naturais, o pendor para o excesso e a prepotência, com a sua sorte favorável, a ponto de os cidadãos de boa reputação a encararem como um perigo, já que facilmente se poderia associar à tirania (16.1-2). No vulgo Alcibíades desperta sentimentos tão contraditórios quanto a sua própria natureza, já que é amado, odiado, e a sua presença desejada.

No contexto de uma Hélade em profunda crise, que se digladia e em que a sorte e o poder, na guerra, facilmente se alteram e favorecem uns ou outros, Alcibíades aprende, por essa mesma incontrolável ambição

positivas lembremos, por exemplo, contextos em que o conceito aparece associado a philodoxia (M. 39e), doxa (e. g. Cam. 31). O adjectivo philotimos com o significado de 'generoso' ocorre em Crass. 3 (philotimos peri xenous). Sobre a história do conceito e a originalidade de Plutarco no uso do termo vide F. Frazier 1988: 109-127. 
e sede de protagonismo, a mudar facilmente de lado e a facilmente persuadir os aliados de momento ou a trai-los, se oportuno, usando a sua synesis kai tolme (21.2, 35.1). Com igual facilidade assume, ou melhor, mimetiza o comportamento honesto e o desonesto, a prática do excesso e os hábitos de pompa, entre os Persas, como os costumes mais sóbrios e severos, entre Espartanos. Tudo isto em função da ambição e do proveito. Para o vulgo esta volúvel e genial adaptação às circunstâncias despertará o sonho da tirania (35.1). Para Plutarco, esta aberração monstruosa de carácter, que se vai agravando com a própria crise da Hélade, assume características comparáveis às de um animal, rastejante - o camaleão (23.3).

Assim, este homem que teve a capacidade de dividir e desestabilizar todo o Peloponeso, que anulou o esforço pacificador de Nícias, converteu-se numa espécie de corporização da própria crise, de materialização do espírito do tempo. Se a ordem da cidade algum paralelismo tem com a ordem da alma, a anomalia de uma physis que Sócrates não conseguiu modelar está em consonância com uma Atenas ao sabor de maiorias movidas pela força tiranizadora de impulsos. É esse o contexto em que se multiplicam os demagogos e os chefes sem escrúpulos, os senhores da guerra, que dela tiram proveito. Assim o frágil rebento da virtude secou, para dar lugar, cada vez mais evidente, aos movimentos do camaleão.

Imitando o ritmo da oscilação deste carácter e do seu destino, Plutarco conclui a comparação das Vitae de Alcibíades e Coriolano com um desfecho teatral: começa por estabelecer um paralelismo que aparenta ser 
favorável em aptidóes a Alcibíades sobre Coriolano para no fim, inesperadamente, operar um volte-face e concluir que a philotimia de Coriolano foi redimida pela sua sophrosyne e pelo desprendimento em relação às riquezas, enquanto Alcibíades se revelou como o homem mais destituído de escrúpulos e mais destituído de sentido moral - to kalon. A sua morte é o quadro que melhor ilustra a sua vida: vítima dos temores da ameaça da tirania que representava e dos sentimentos contraditórios que a sua doxa despertava, vítima das intrigas que semeou, envolvido, ambiguamente, em roupas de cortesâ, ou pura e simplesmente apanhado em fuga depois de saciar o seu eros. Um dia chegou em que o sonho fatalmente se cumpriu, esfumada, de todo, a influência de Sócrates sobre uma natureza promissora que por prazeres, adulação e cupidez se desintegrou numa desordem de alma e de acção. 